\title{
Degree of Hyper-Dynamic Circulation Correlates with the Severity of Liver Disease and Predicts Poor Outcome in Spontaneous Bacterial Peritonitis Patients in Intensive Care Unit
}

\author{
Mohamed Hamdi Saleh1, Ahmed Hamdy², Moataz Elhalag1 \\ ${ }^{1}$ Critical Care Medicine Department, Faculty of Medicine, Cairo University, Giza, Egypt \\ ${ }^{2}$ Internal Medicine Department, Faculty of Medicine, Cairo University, Giza, Egypt \\ Email: ahramadan777@gmail.com
}

How to cite this paper: Saleh, M.H., Hamdy, A. and Elhalag, M. (2017) Degree of Hyper-Dynamic Circulation Correlates with the Severity of Liver Disease and Predicts Poor Outcome in Spontaneous Bacterial Peritonitis Patients in Intensive Care Unit. Open Journal of Gastroenterology, 7, 105-114.

https://doi.org/10.4236/ojgas.2017.73012

Received: February 3, 2017

Accepted: March 26, 2017

Published: March 29, 2017

Copyright () 2017 by authors and Scientific Research Publishing Inc. This work is licensed under the Creative Commons Attribution International License (CC BY 4.0).

http://creativecommons.org/licenses/by/4.0/

\begin{abstract}
Background: Circulatory dysfunction is known in spontaneous bacterial peritonitis (SBP) patients. We aimed to determine whether degree of hyper-dynamic circulation is significantly correlated with severity of liver disease and poor outcome in these patients or not. Methods: 61 patients diagnosed to have SBP were enrolled. In addition to routine laboratory investigation, Child Pugh and APACHE II scores were calculated for all patients. Degree of renal impairment was defined using Acute Kidney Injury Network (AKIN) criteria. Stroke volume (SV) was measured by $\mathrm{M}$ mode and 2-dimensional Doppler echocardiography. Cardiac output (CO) and Systemic vascular resistance (SVR) were also calculated. All data were statistically analyzed. Results: SV, CO, SVR were significantly correlated with Child Pugh score, $\mathrm{p}$ value $<0.001,<0.001$, and 0.011 respectively. In $46(75.4 \%)$ patients who had AKI, degree of kidney injury using AKIN criteria is significantly correlated with SVR, SV, and CO. Inpatient mortality occurred in $10(16.4 \%)$ patients. Non-survivors had lower SVR and higher SV and CO compared to survivors $\left(1805 \pm 105 \mathrm{dyn} \cdot \mathrm{sec} / \mathrm{cm}^{2}\right.$, $80.3 \pm 11.2 \mathrm{ml}$, and $6.7 \pm 1.1 \mathrm{~L} / \mathrm{min}$ vs $1936 \pm 504,67.6 \pm 12.7$, and $5.7 \pm 0.9, \mathrm{p}$ value $0.029,0.005,0.007$ respectively). Using the Receiver Operating Characteristics (ROC) curve, the cut-off value of $\mathrm{CO}$ that predicts mortality was 5.89 $\mathrm{L} / \mathrm{min}$ with sensitivity and specificity measuring $80 \%, 70.6 \%$ respectively. The area under the curve (AUC) is 0.767 with $95 \%$ confidence interval (CI) is 0.566 to $0.968, p$ value 0.008 . At this value, the odds ratio (OR) is 7.33 with $p$ value 0.012 . Conclusion: Degree of hyper-dynamic circulation is significantly correlated with the severity of liver disease and predicts poor outcome in SBP patients.
\end{abstract}




\section{Keywords}

Spontaneous Bacterial Peritonitis, Acute Kidney Injury, AKIN Criteria

\section{Introduction}

Spontaneous bacterial peritonitis (SBP) is a serious and relatively common complication in patients with advanced liver cell failure [1] [2] [3]. Circulatory dysfunction attributed to an increased local release of nitric oxide (NO) and other vasodilators related to portal hypertension has been reported which lead to splanchnic arterial vasodilatation with subsequent decrease in systemic vascular resistance (SVR) [4] [5]. Increased cardiac output (CO) and over-activity of the renin-angiotensin system (RAS), sympathetic nervous system, and antidiuretic hormone $(\mathrm{ADH})$ are essential compensatory mechanisms in order to maintain arterial blood pressure in these patients [2]. Navasa et al., [6] suggested that renal failure in SBP is due to this circulatory dysfunction promoted by cytokines that result in further stimulation of the RAS and sympathetic nervous systems that lead to renal vasoconstriction, and reduction in glomerular filtration rate [6] [7]. The occurrence of renal failure in SBP in association with extremely high plasma and ascetic fluid levels of inflammatory mediators such as tumor necrosis factor (TNF) and interleukin 6 (IL-6) may indicate that these inflammatory mediators may play another role in circulatory dysfunction in these patients [4] [8].

Our aim was to determine whether degree of hyper-dynamic circulation is correlated with severity of the liver disease and poor outcome in SBP patients admitted to intensive care unit or not.

\section{Patients and Methods}

This observational prospective study was conducted on 61 patients admitted to critical care department of Cairo university Hospitals with SBP during the period between March to September 2015. SBP was defined as presence of $\geq 250$ polymorph nuclear cells with absence of any cause suggestive secondary bacterial peritonitis [9].

All patients underwent full clinical examination and laboratory investigation including CRP and blood gases. APACHE II, and Child- Pugh scores was calculated upon admission. Degree of renal impairment was assessed using AKIN criteria into grades 1, 2, and 3 [9].

Hemodynamic measurements: Stroke volume (SV) was measured by M mode and 2-dimensional Doppler echocardiography with an ACUSON X300 equipped with $4-2 \mathrm{MHz}$ transducer. Cardiac output (CO) was calculated as the product of SV and heart rate. Systemic vascular resistance (SVR) was calculated as the ratio of mean arterial pressure to cardiac output $\mathrm{x} 80$.

Management: All patients were treated with high dose IV albumin and 3rd generation cephalosporin. Antibiotics were modified according to culture re- 
sults, or if the cytological response was not achieved. Patients with renal impairment were treated with IV terlipressin and oral midodrine. All patients with any of the following were excluded: age $<18$ years, admission with hemodynamic instability, patients underwent large volume paracentesis, hepatocellular carcinoma, presence of any source of sepsis other than SBP, pre existing renal impairment, any cause of hyperdynamic circulation including sepsis other than SBP, thyrotoxicosis, and previous arteriovenous shunts. Patients with hepatic encephalopathy were treated with Oral lactulose, lactulose enema and Rifaxamine at a dose of $4000 \mathrm{mg} 3$ times a day.

\section{Statistical Analysis}

Data were analyzed using SPSS (Statistical Package for the Social Sciences) software package version 18.0 (SPSS, Chicago, IL, USA). Quantitative data were expressed using Range, Mean, standard deviation and Median while Qualitative data was expressed in frequency and percent. Qualitative data was analyzed using Chi-square test also exact tests such Fisher exact and Monte Carlo was applied to compare different groups. Quantitative data was analyzed using student t-test to compare between two groups. Non-normally distributed quantitative data were analyzed using Mann Whitney test for comparing two groups. $\mathrm{P}$ value was assumed to be significant at 0.05 .

\section{Results}

61 patients with mean age of $56.8 \pm 5.9$ years admitted to the critical care medicine department and diagnosed to have SBP were enrolled. Baseline general characteristics, standard laboratory results, and hemodynamic measurements of the studied patients are shown in Table 1, and Table 2.

Pearson correlation showed that SV, CO, SVR were significantly correlated with Child Pugh score, $\mathrm{p}$ value $<0.001,<0.001$, and 0.011 respectively (Figure 1 , Figure 2, Figure 3).

AKI occurred in 46 (75.4\%) patients. Of them, 18 (29.5\%), 17 (27.9\%), 18 (29.5\%) had AKIN grade 1, 2, and 3 respectively. Degree of renal impairment as defined with AKIN criteria was associated with more derangement in hemodynamic indices namely: SVR, SV, and CO (Table 3).

Inpatient mortality occurred in $10(16.4 \%)$ patients. All mortality exclusively occurred in patients AKI during their hospital course: 9 (90\%) and 1 (10\%) patients had AKIN grade 3 and 2 respectively (Figure 4).

Non-survivors had lower SVR and higher SV and CO compared to survivors $\left(1805 \pm 105 \mathrm{dyn} \cdot \mathrm{sec} / \mathrm{cm}^{2}, 80.3 \pm 11.2 \mathrm{ml}\right.$, and $6.7 \pm 1.1 \mathrm{~L} / \mathrm{min}$ vs $1936 \pm 504,67.6$ \pm 12.7 , and $5.7 \pm 0.9$, p value $0.029,0.005,0.007$ respectively) (Table 4 ).

Using the Receiver Operating Characteristics (ROC) curve, the cut-off value of $\mathrm{CO}$ that predict mortality was 5.89 with sensitivity and specificity measuring $80 \%, 70.6 \%$ respectively. The area under the curve (AUC) is 0.767 and $95 \%$ confidence interval (CI) is 0.566 to 0.968 , p value 0.008 (Figure 5 ). At this value, the odds ratio (OR) is 7.33 with $\mathrm{p}$ value 0.012 . 
Table 1. General characteristics and standard laboratory results for studied patients.

\begin{tabular}{|c|c|}
\hline Variables & Mean \pm SD \\
\hline Age (years) & $56.86 \pm 5.97$ \\
\hline $\operatorname{Sex}(ð \%)$ & $65.6 \%$ \\
\hline APACHE II score (points) & $17.24 \pm 2.61$ \\
\hline Child Pugh (points) & $9.52 \pm 1.42$ \\
\hline $\mathrm{Hb}(\mathrm{mg} / \mathrm{dl})$ & $9.48 \pm 1.07$ \\
\hline Bilirubin. T (mg/dl) & $4.20 \pm 2.26$ \\
\hline Bilirubin. D (mgl/dl) & $2.69 \pm 1.76$ \\
\hline $\operatorname{PLT}\left(\times 10^{3} / \mathrm{cmm}\right)$ & $79.21 \pm 28.22$ \\
\hline PC (\%) & $50.16 \pm 12.45$ \\
\hline $\mathrm{Na}(\mathrm{mmol} / \mathrm{l})$ & $128.75 \pm 4.93$ \\
\hline $\mathrm{Cr}(\mathrm{mg} / \mathrm{dl})$ & $1.85 \pm 1.48$ \\
\hline $\mathrm{CRP}(\mathrm{mg} / \mathrm{dl})$ & $91.54 \pm 26.47$ \\
\hline Lactate $(\mathrm{mmol} / \mathrm{l})$ & $1.77 \pm 0.59$ \\
\hline
\end{tabular}

Abbreviations: Hb: hemoglobin, PLT: platelets, PC: prothrombin concentration, Cr: Creatinine, CRP Creactive protein. Data are presented as mean \pm SD or percentage $\%$.

Table 2. Hemodynamic measurements of the studied patients.

\begin{tabular}{cc}
\hline Hemodynamic variables & Mean \pm SD \\
\hline SV $(\mathrm{ml})$ & $69.69 \pm 13.3$ \\
CO $(\mathrm{L} / \mathrm{min})$ & $5.93 \pm 1.01$ \\
SVR $\left(\right.$ dyn $\left.\cdot \mathrm{sec} / \mathrm{cm}^{5}\right)$ & $1914 \pm 464$ \\
\hline
\end{tabular}

Abbreviations: SV: stroke volume, CO: cardiac output, SVR: systemic vascular resistance. Data are presented as mean $\pm \mathrm{SD}$.

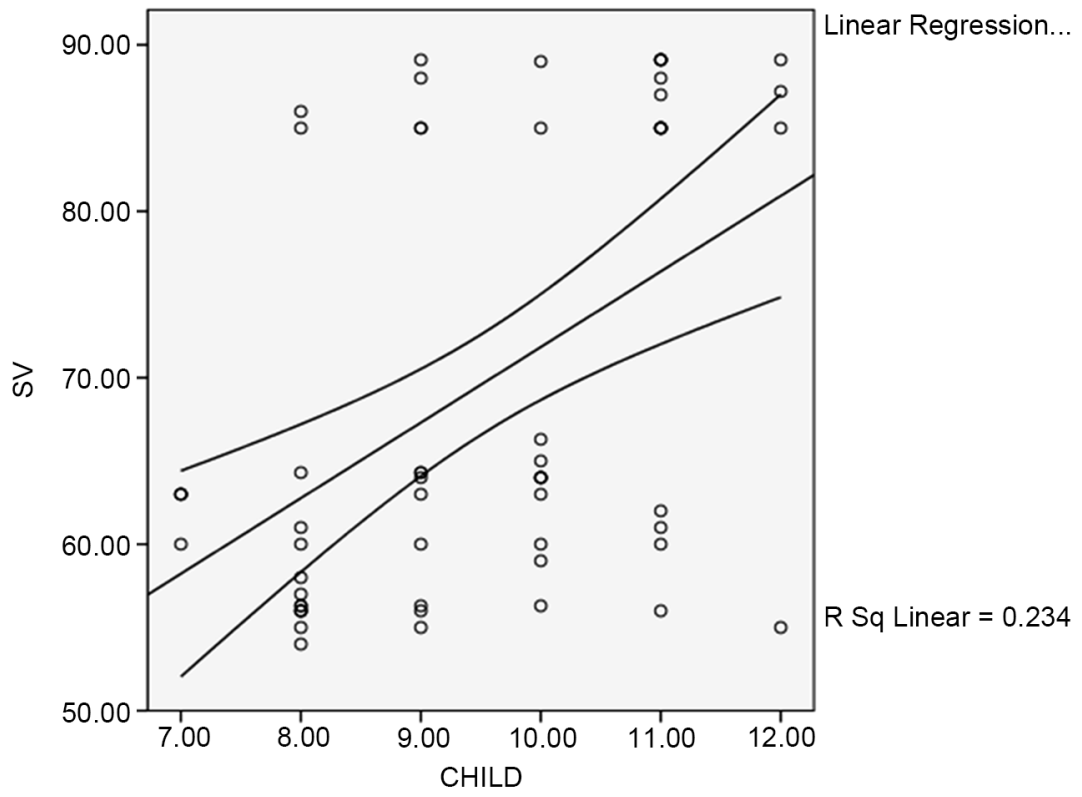

Figure 1. Correlation between SV and child pugh in the studied patients. 


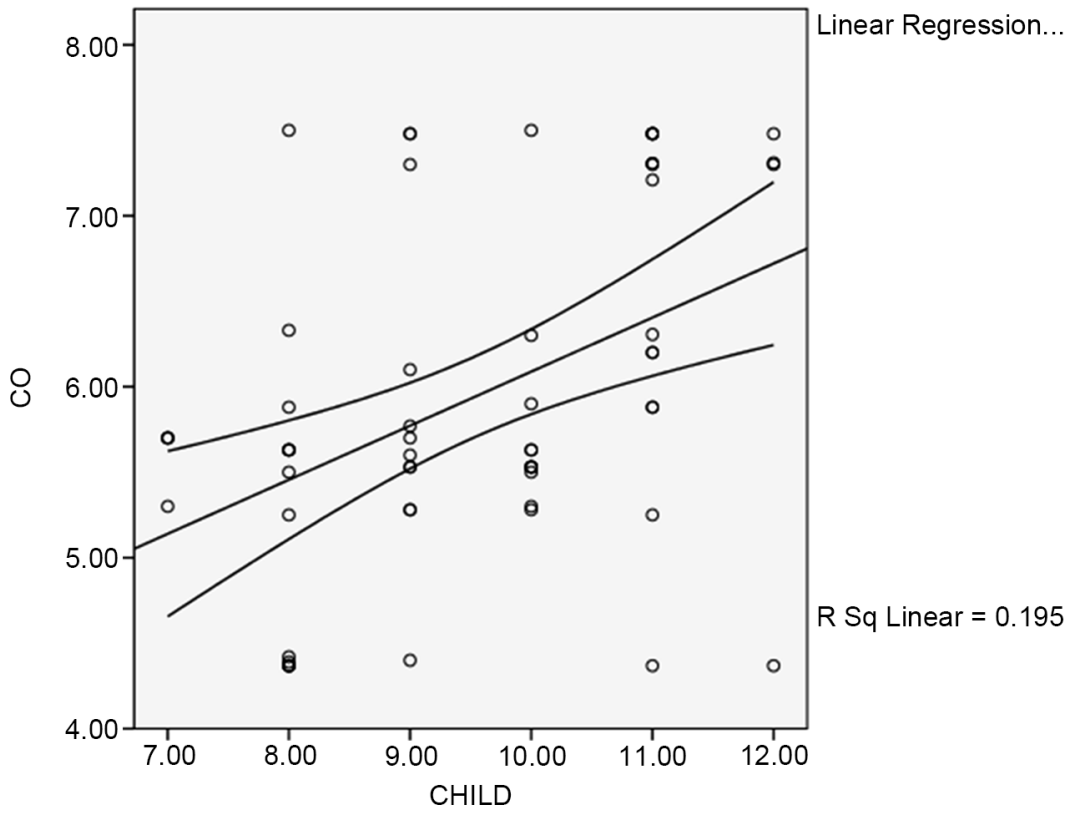

Figure 2. Correlation between $\mathrm{CO}$ and child pugh in the studied patients.

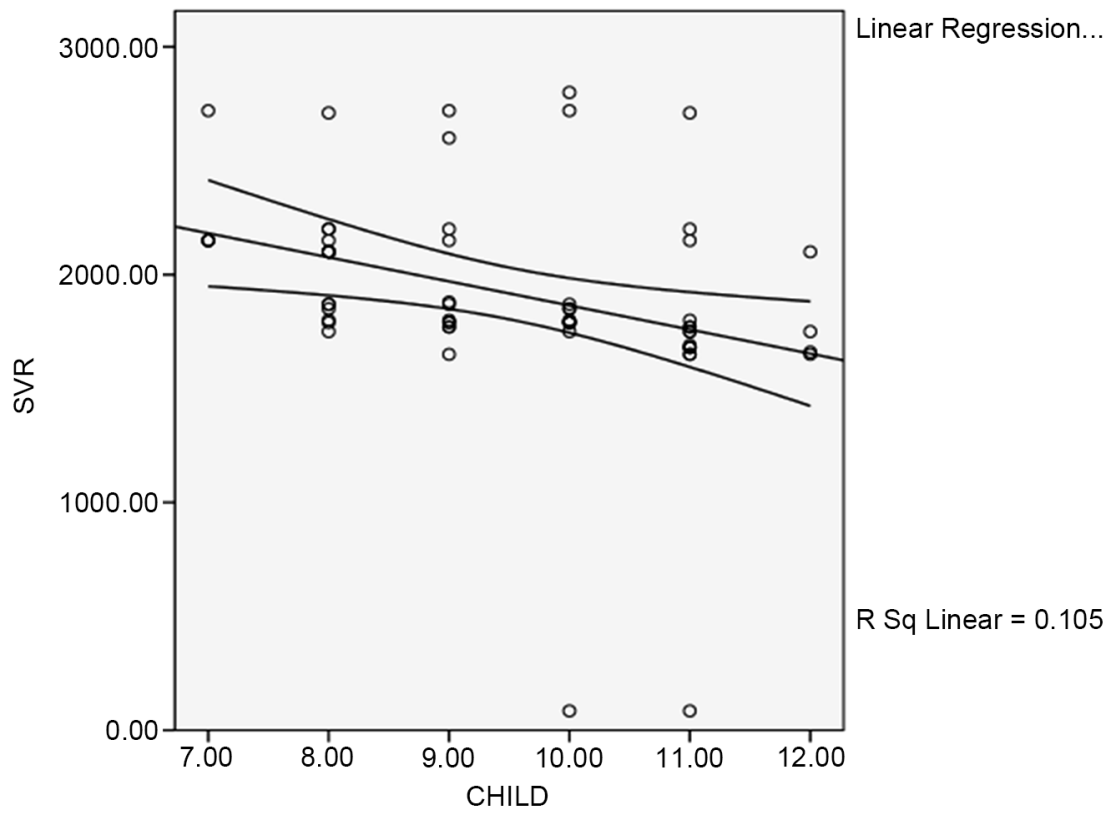

Figure 3. Correlation between SVR and child pugh in the studied patients.

Table 3. Hemodynamic measurements in relation to degree of renal impairment of the studied patients.

\begin{tabular}{cccccc}
\hline & AKIN 0 & AKIN 1 & AKIN 2 & AKIN 3 & P value \\
\hline SV (ml) & $64.0 \pm 12.07$ & $67.5 \pm 11.9$ & $71.6 \pm 13.8$ & $78.0 \pm 13.0$ & 0.046 \\
CO (L/min) & $5.3 \pm 1.09$ & $5.6 \pm 0.61$ & $6.36 \pm 0.83$ & $6.61 \pm 1.1$ & 0.001 \\
SVR (dyn.sec/cm $)$ & $1987 \pm 195$ & $2142 \pm 438$ & $1678 \pm 659$ & $1810 \pm 103$ & 0.018 \\
\hline
\end{tabular}

Abbreviations: AKIN: Acute Kidney Injury Network, SV: stroke volume, CO: cardiac output, SVR: systemic vascular resistance. Data are presented as mean \pm SD. 
Table 4. Hemodynamic indices in relation to mortality.

\begin{tabular}{cccc}
\hline & Survivors & Non survivors & P value \\
\hline $\mathrm{SV}(\mathrm{ml})$ & $67.6 \pm 12.7$ & $80.3 \pm 11.2$ & 0.005 \\
$\mathrm{CO}(\mathrm{L} / \mathrm{min})$ & $5.7 \pm 0.9$ & $6.7 \pm 1.1$ & 0.007 \\
$\mathrm{SVR}\left(\mathrm{dyn} \cdot \mathrm{sec} / \mathrm{cm}^{5}\right)$ & $1936 \pm 504$ & $1805 \pm 105$ & 0.029 \\
\hline
\end{tabular}

Abbreviations: SV: stroke volume, CO: cardiac output, SVR: systemic vascular resistance. Data are presented as mean $\pm \mathrm{SD}$.

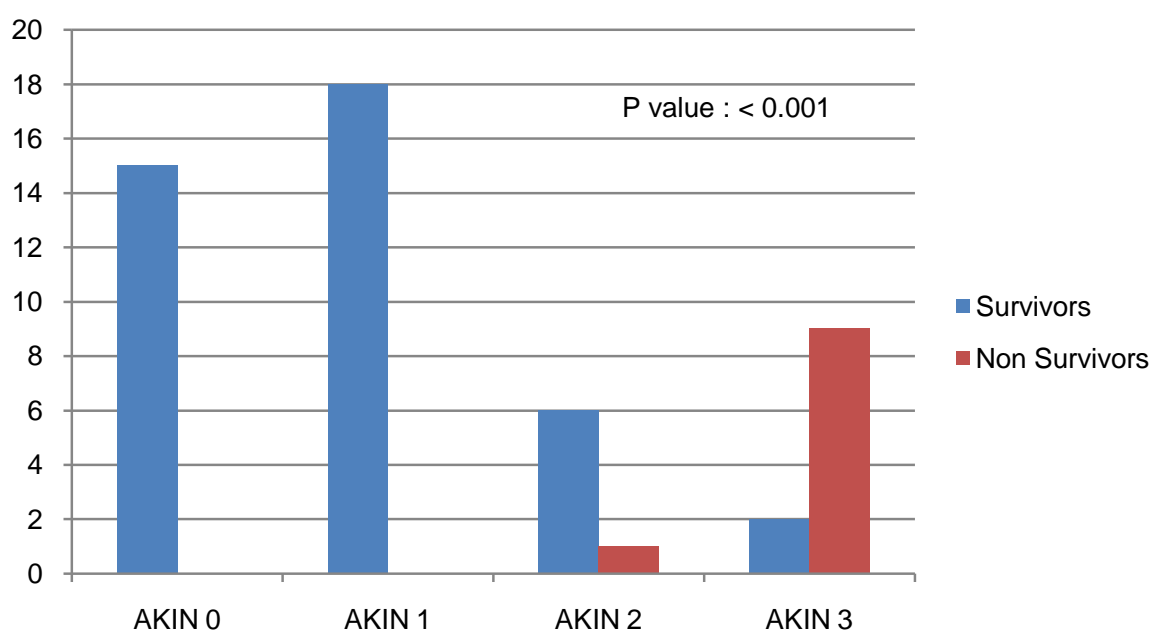

Figure 4. Degree of AKIN grade in relation to mortality.

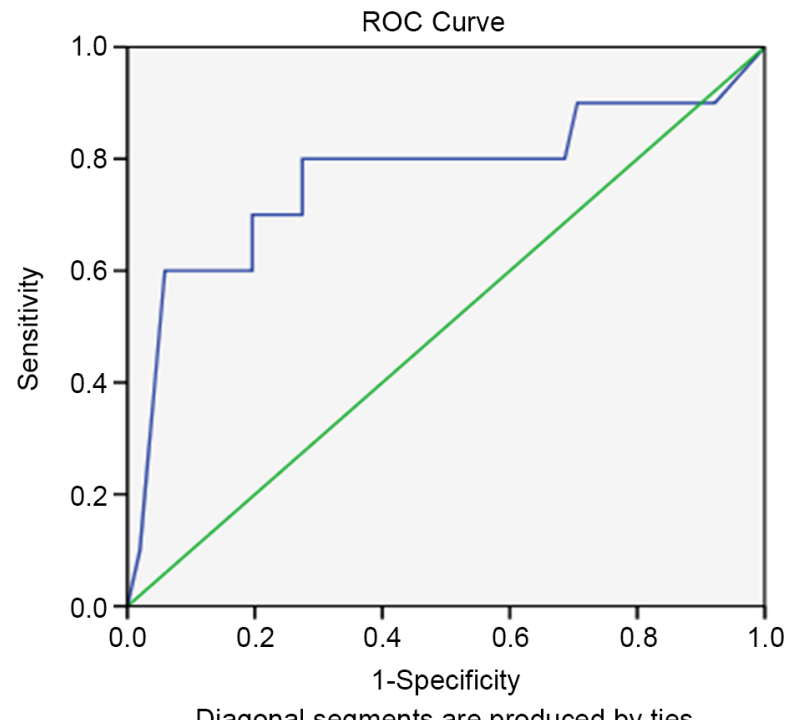

Figure 5. ROC curve for $\mathrm{CO}$ as a predictor of mortality.

\section{Discussion}

Hyper-dynamic circulation in patients with liver cirrhosis arises from portal hypertension and portosystemic shunts developed to counterbalance the increased intra-hepatic vascular resistance to portal blood flow with subsequent increase in venous return to heart. Increased shear stress in vascular endothelial 
cell related high blood flow by portosystemic shunting contributes to this up-regulation of eNOS resulting in NO overproduction. Nonetheless, bypassing through portosystemic collaterals and escaping degradation of over-produced circulating vasodilators in the diseased liver can promote the peripheral arterial vasodilation that lead to a reduced SVR, and increased SV, CO and splanchnic blood flow [10].

The present study showed that the degree of hyper-dynamic circulation was significantly correlated with Child pugh score, degree of renal impairment, and mortality in SBP patients admitted to ICU which was in concordance with Fernandez-Seara, et al. and Iwao, T., et al. [11] [12] who demonstrated that the degree of hepatic decompensation directly correlates with the degree of hyper-dynamic circulation and inversely correlates with the arterial BP. These results were supported by many studies reported improvement in the hemodynamic and neurohormonal parameters and reversal of renal impairment with systemic vasoconstrictor administration [13]-[18]. Studies in animal models and humans with cirrhosis consistently demonstrate that the splanchnic circulation is the main vascular bed responsible for the peripheral vasodilation, especially in advanced liver disease [11] [19] [20] [21].

In contrast to our results, Ruiz-del-Arbol, et al., [22] demonstrated reduction in CO without a change SVR in SBP patients who developed HRS. This contradiction could be explained by the difference of etiology of liver cirrhosis in their patients compared to our patients, as the majority (15/23) of their patients had alcoholic cirrhosis and only $8 / 23$ had HCV related cirrhosis. In contrast, all of our patients had HCV related cirrhosis and none had alcoholic cirrhosis. Thus, a variable degree of alcoholic cardiomyopathy could be a contributing factor in hemodynamic alteration of their patients. Moreover, we excluded all patients with previous renal impairment while they included any patients who had serum creatinine level below $3 \mathrm{mg} / \mathrm{dl}$ on admission.

This study also showed that the overall mortality in the studied patients was $16.4 \%$ patients and it was exclusively happened in patients who developed AKI. In agreement with our results, Tsung-Hsing, H., et al., [22] proved that acute renal failure is a better determinant of short and long term mortality in SBP patients. Similarly, Folo, et al., [8] reported that with renal impairment, the mortality rate increased from $9 \%$ to $54 \%$ in SBP patients.

In the present study, the parameters of hyper-dynamic circulation were significantly higher in non survivors compared to survivors. To the best of our knowledge, no previous studies correlate the parameters of hyper-dynamic circulation with mortality in cirrhotic or SBP patients. However, Navasa, M., et al., [6] noted that cirrhotic patients who developed renal function impairment, which was the main predictor of mortality in these patients as mentioned before, had higher levels of cytokine in the serum and ascitic fluid. In addition, they also mentioned that SBP induced higher serum renin levels in cirrhotic patients with acute renal failure, compared with those without ARF. Thus, it is postulated that cytokines lead to NO release, which in turn results in arterial vasodilatation and 
hemodynamic alterations that may cause ARF. Therefore, the occurrence of ARF after SBP may present a combination of infection-induced circulatory failure and cirrhosis-related circulatory failure. Hence, we recommend to routinely assessing the parameters of hyper-dynamic circulation in all SBP patients admitted to ICU.

Study limitations: In addition to relatively small sample size, we measured the parameters of hyper-dynamic circulation once on admission, and we didn't monitor them during the hospital stay to assess their trends and correlate these trends with mortality. Also, we didn't study the effect of various vasoactive agents on these parameters.

We concluded from this study that the degree of hyper-dynamic circulation was significantly correlated with the severity of liver disease and predicted poor outcome of SBP patients admitted to ICU.

\section{References}

[1] Rimola, A., Garcia-Tsao, G., Navasa, M., Piddock, L.J., Planas, R., Bernard, B. and Inadomi, J.M. (2000) Diagnosis, Treatment, and Prophylaxis of Spontaneous Bacterial Peritonitis: A Consensus Document. Journal of Hepatology, 32, 142-153. https://doi.org/10.1016/S0168-8278(00)80201-9

[2] Runyon, B.A. (2009) Management of Adult Patient with Ascites Due to Cirrhosis: An Update. Hepatology, 49, 2087-2107. https://doi.org/10.1002/hep.22853

[3] DeAraujo, A. and Alvares-da-Silva, M.R. (2014) Akin Criteria as a Predictor of Mortality in Cirrhotic Patients after Spontaneous Bacterial Peritonitis. Annals of Hepatology, 13, 390-395.

[4] Schrier, R.W., Arroyo, V., Bernardi, M., Epstein, M., Henriksen, J.H. and Rodes, J. (1988) Peripheral Arterial Vasodilation Hypothesis: A Proposal for the Initiation of Renal Sodium and Water Retention in Cirrhosis. Hepatology, 8, 1151-1157. https://doi.org/10.1002/hep.1840080532

[5] Wiest, R. and Groszmann, R.J. (2002) The Paradox of Nitric Oxide in Cirrhosis and Portal Hypertension: Too Much, Not Enough. Hepatology, 35, 478-491. https://doi.org/10.1053/jhep.2002.31432

[6] Navasa, M., Follo, A., Filella, X., Jimenez, W., Francitorra, A., Planas, R., Rimola, A., et al. (1998) Tumor Necrosis Factor and Interleukin-6 in Spontaneous Bacterial Peritonitis in Cirrhosis: Relationship with the Development of Renal Impairment and Mortality. Hepatology, 27, 1227-1232. https://doi.org/10.1002/hep.510270507

[7] Sort, P., Navasa, M., Arroyo, V., Aldeguer, X., Planas, R., Ruiz-del-Arbol, L., Castells, L., et al. (1999) Effect of Intravenous Albumin on Renal Impairment and Mortality in Patients with Cirrhosis and Spontaneous Bacterial Peritonitis. The New England Journal of Medicine, 5, 403-409. https://doi.org/10.1056/NEJM199908053410603

[8] Follo, A., Llovet, J.M., Navasa, M., Planas, R., Forns, X., Francitorra, A., Rimola, A., et al. (1994) Renal Impairment after Spontaneous Bacterial Peritonitis in Cirrhosis: Incidence, Clinical Course, Predictive Factors and Prognosis. Hepatology, 20, 1495 1501. https://doi.org/10.1002/hep.1840200619

[9] DeArujo, A. and Alvares da Silva, M.R. (2014) Akin Criteria as a Predictor of Mortality in Cirrhotic Patients after Spontaneous Bacterial Peritonitis. Annals of Hepatology, 13, 390-395. 
[10] Kim, M.Y. and Baik, S.K. (2009) Hyperdynamic Circulation in Patients with Liver Cirrhosis and Portal Hypertension. The Korean Journal of Gastroenterology, 54, 143-148. https://doi.org/10.4166/kjg.2009.54.3.143

[11] Fernandez-Seara, J., Prieto, J., Quiroga, J., Zozaya, J.M., Cobos, M.A., RodriguezEire, J.L., Garcia-Plaza, A. and Leal, J. (1989) Systemic and Regional Hemodynamics in Patients with Liver Cirrhosis and Ascites with and without Functional Renal Failure. Gastroenterology, 97, 1304-1312. https://doi.org/10.1016/0016-5085(89)91704-6

[12] Iwao, T., Oho, K., Sakai, T., Tayama, C., Sato, M., Nakano, R., Yamawaki, M., Toyonaga, A. and Tanikawa, K. (1997) Splanchnic and Extrasplanchnic Arterial Hemodynamics in Patients with Cirrhosis. Journal of Hepatology, 27, 817-823. https://doi.org/10.1016/S0168-8278(97)80318-2

[13] Colle, I., Durand, F., Pessione, F., Rassiat, E., Bernuau, J., Barriere, E., Lebrec, D., Valla, D.C. and Moreau, R. (2002) Clinical Course, Predictive Factors and Prognosis in Patients with Cirrhosis and Type 1 Hepatorenal Syndrome Treated with Terlipressin: A Retrospective Analysis. Journal of Gastroenterology and Hepatology, 17, 882-888. https://doi.org/10.1046/j.1440-1746.2002.02816.x

[14] Ortega, R., Gines, P., Uriz, J., Cardenas, A., Calahorra, B., De Las Heras, D., Guevara, M., Bataller, R., Jimenez, W., Arroyo, V. and Rodes, J. (2002) Terlipressin Therapy with and without Albumin for Patients with Hepatorenal Syndrome: Results of a Prospective, Nonrandomized Study. Hepatology, 36, 941-948. https://doi.org/10.1053/jhep.2002.35819

[15] Uriz, J., Gines, P., Cardenas, A., Sort, P., Jimenez, W., Salmeron, J.M., Bataller, R., Mas, A., Navasa, M., Arroyo, V. and Rodes, J. (2000) Terlipressin Plus Albumin Infusion: An Effective and Safe Therapy of Hepatorenal Syndrome. Journal of Hepatology, 33, 43-48. https://doi.org/10.1016/S0168-8278(00)80158-0

[16] Alessandria, C., Venon, W.D., Marzano, A., Barletti, C., Fadda, M. and Rizzetto, M. (2002) Renal Failure in Cirrhotic Patients: Role of Terlipressin in Clinical Approach to Hepatorenal Syndrome Type 2. European Journal of Gastroenterology and Hepatology, 14, 1363-1368. https://doi.org/10.1097/00042737-200212000-00013

[17] Solanki, P., Chawla, A., Garg, R., Gupta, R., Jain, M. and Sarin, S.K. (2003) Beneficial Effects of Terlipressin in Hepatorenal Syndrome: A Prospective, Randomized Placebo-Controlled Clinical Trial. Journal of Gastroenterology and Hepatology, 18, 152-156. https://doi.org/10.1046/j.1440-1746.2003.02934.x

[18] Moreau, R., Durand, F., Poynard, T., Duhamel, C., Cervoni, J.P., Ichai, P., Abergel, A., Halimi, C., Pauwels, M., Bronowicki, J.P., Giostra, E., Fleurot, C., Gurnot, D., Nouel, O., Renard, P., Rivoal, M., Blanc, P., Coumaros, D., Ducloux, S., Levy, S., Pariente, A., Perarnau, J.M., Roche, J., Scribe-Outtas, M., Valla, D., Bernard, B., Samuel, D., Butel, J., Hadengue, A., Platek, A., Lebrec, D. and Cadranel, J.F. (2002) Terlipressin in Patients with Cirrhosis and Type 1 Hepatorenal Syndrome: A Retrospective Multicenter Study. Gastroenterology, 122, 923-930.

https://doi.org/10.1053/gast.2002.32364

[19] Vorobioff, J., Bredfeldt, J.E. and Groszmann, R.J. (1984) Increased Blood Flow through the Portal System in Cirrhotic Rats. Gastroenterology, 87, 1120-1126.

[20] Sato, S., Ohnishi, K., Sugita, S. and Okuda, K. (1987) Splenic Artery and Superior Mesenteric Artery Blood Flow: Nonsurgical Doppler US Measurement in Healthy Subjects and Patients with Chronic Liver Disease. Radiology, 164, 347-352. https://doi.org/10.1148/radiology.164.2.2955448

[21] Ohnishi, K., Sato, S., Pugliese, D., Tsunoda, T., Saito, M. and Okuda, K. (1987) Changes of Splanchnic Circulation with Progression of Chronic Liver Disease Stu- 
died by Echo-Doppler Flowmetry. The American Journal of Gastroenterology, 82, 507-511.

[22] Hung, T.H., Tsal, C.C., Hsieh, Y.H., Tsai, C.C., Tseng, C.W. and Tsai, J.J. (2012) Effect of Renal Impairment on Mortality of Patients with Cirrhosis and Spontaneous Bacterial Peritonitis. Clinical Gastroenterology and Hepatology, 10, 677-681. https://doi.org/10.1016/j.cgh.2012.02.026

Submit or recommend next manuscript to SCIRP and we will provide best service for you:

Accepting pre-submission inquiries through Email, Facebook, LinkedIn, Twitter, etc. A wide selection of journals (inclusive of 9 subjects, more than 200 journals)

Providing 24-hour high-quality service

User-friendly online submission system

Fair and swift peer-review system

Efficient typesetting and proofreading procedure

Display of the result of downloads and visits, as well as the number of cited articles Maximum dissemination of your research work

Submit your manuscript at: http://papersubmission.scirp.org/

Or contact ojgas@scirp.org 